\title{
Bilateral adrenal phaeochromocytomas associated with unilateral renal artery stenosis
}

\author{
Aine P. Burns, P. Ronan O'Connell, Dermot J. Murnaghan and Michael P. Brady \\ Departments of Medicine and Surgery, Regional Hospital and University College, Cork, Ireland.
}

\begin{abstract}
Summary: A 21 year old male was discovered to be severely hypertensive. He was found to have bilateral adrenal phaeochromocytomas and a single renal artery stenosis. More than $\mathbf{4 0}$ cases of coexisting renal artery stenosis and phaeochromocytomas have been reported. The aetiology of renal artery stenosis in association with phaeochromocytoma maybe multifactorial and the radiographic appearances are not always clear-cut.

Renin levels in this patient were elevated prior to the removal of the phaeochromocytomas but the renal vein renin ratio did not suggest that the renal artery stenosis contributed significantly to his hypertension. The patient's hypertension resolved following successful removal of the phaeochromocytomas despite persistence of the renal artery stenosis. Thus, though renin levels may be misleading in these cases, renal vein renin ratios may still be helpful in deciding on patient management.
\end{abstract}

\section{Introduction}

The co-existence of renal artery stenosis and phaeochromocytoma has been recognized since 1958 . Over 40 cases have now been reported. We report a case of bilateral adrenal phaeochromocytomas together with unilateral renal artery stenosis. To our knowledge this is the first such case reported. We discuss the possible pathogenesis, the angiographic findings and the value of renin estimations in these patients.

\section{Case report}

A 21 year old male Caucasian was admitted for head injury observations following a minor road traffic accident. He suffered no other significant injury. He claimed to have been previously well. He had no family history of note. On physical examination he was alert and orientated. His pulse was $90 / \mathrm{min}$ and regular. His blood pressure was $190 / 120 \mathrm{mmHg}$ (supine) and $90 / 70 \mathrm{mmHg}$ (erect). A right renal bruit was heard. On fundoscopy he had arteriolar narrowing and arterio-venous nipping. The remainder of his physical examination was unremarkable. Ward urinalysis showed the presence of $2+$ protein. Chest $\mathrm{X}$-ray, routine haematology and biochemistry, as well as creatinine clearance, were normal. The electro-

Correspondence: A.P. Burns, M.R.C.P.I., The Renal Unit, Royal Postgraduate Medical School, Hammersmith Hospital, Du Cane Road, London W12 0NN, UK.

Accepted: 10 March 1989 cardiogram showed left ventricular hypertrophy with a strain pattern in the lateral leads.

A percutaneous transfemoral renal angiogram was performed. This revealed a normal left kidney and normal left renal artery. The right kidney was supplied by two main arteries, the upper and larger of which had a smooth stenosis just proximal to its bifurcation. The lower artery appeared normal in calibre throughout its length (Figure 1). In addition, a large mass was noted over the upper pole of the right kidney. The position and vascularity of this mass was consistent with a phaeochromocytoma (Figure 2).

During angiography the patient became severely hypertensive $(200 / 140 \mathrm{mmHg})$. Blood pressure returned to normal immediately on intravenous administration of phentolamine. Twenty four hour urinary excretion of vanillylmandelic acid (VMA) was markedly elevated at $204 \mu \mathrm{mol} / 24 \mathrm{~h}$ (normal 5-45 $\mathrm{mol} / 24 \mathrm{~h}$ ). Plasma noradrenaline levels were also grossly elevated at $9622 \mathrm{pg} / \mathrm{ml}$ supine (normal $290 \pm 105 \mathrm{pg} / \mathrm{ml}$ ) and $13174 \mathrm{pg} / \mathrm{ml}$ erect (normal $710 \pm 300 \mathrm{pg} / \mathrm{ml}$ ). Peripheral plasma renin levels were slightly elevated at $5.3 \mathrm{pmol} / \mathrm{ml} / \mathrm{h}$ supine on a normal salt diet (normal $1-5 \mathrm{pmol} / \mathrm{ml} / \mathrm{h}$ ). Selective venous samples for renin were taken during angiography and these demonstrated high values at every site including both right and left renal veins $(15.9$ and $12.7 \mathrm{pmol} / \mathrm{ml} / \mathrm{h}$ respectively). The renal vein renin ratio did not, however, exceed 1.5 and was therefore not diagnostic of renovascular hypertension. A diagnosis of right adrenal phaeochromocytoma with co-existing right sided renal artery stenosis was made. A second 


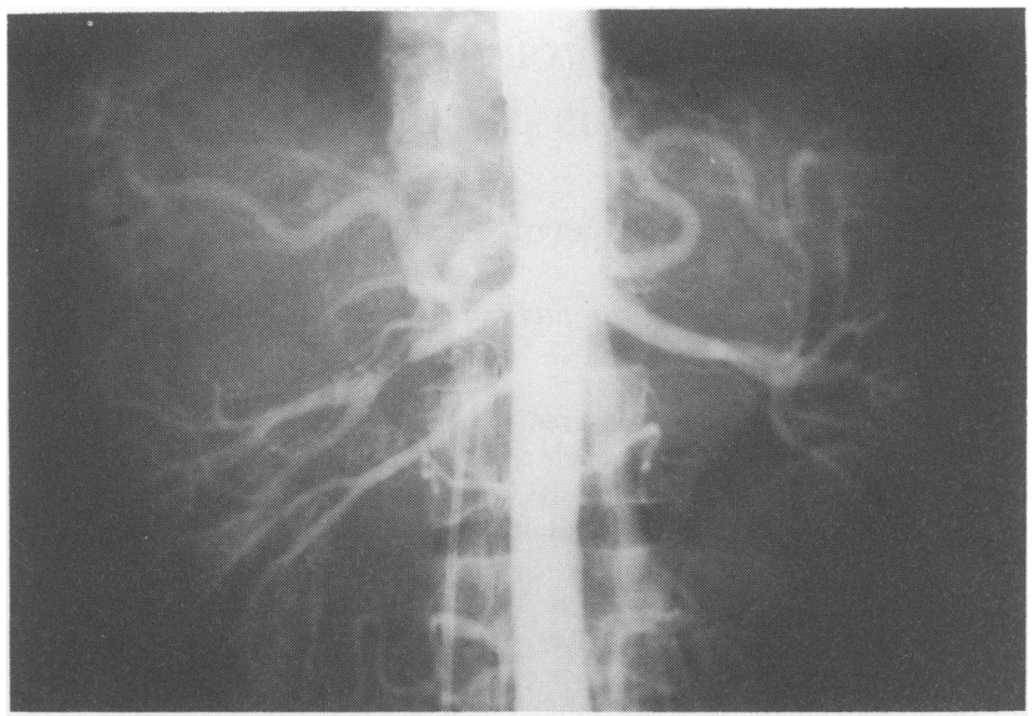

Figure 1 Renal angiogram. The right kidney is supplied by two renal arteries, the upper and larger of which has a smooth stenosis just proximal to its bifurcation.

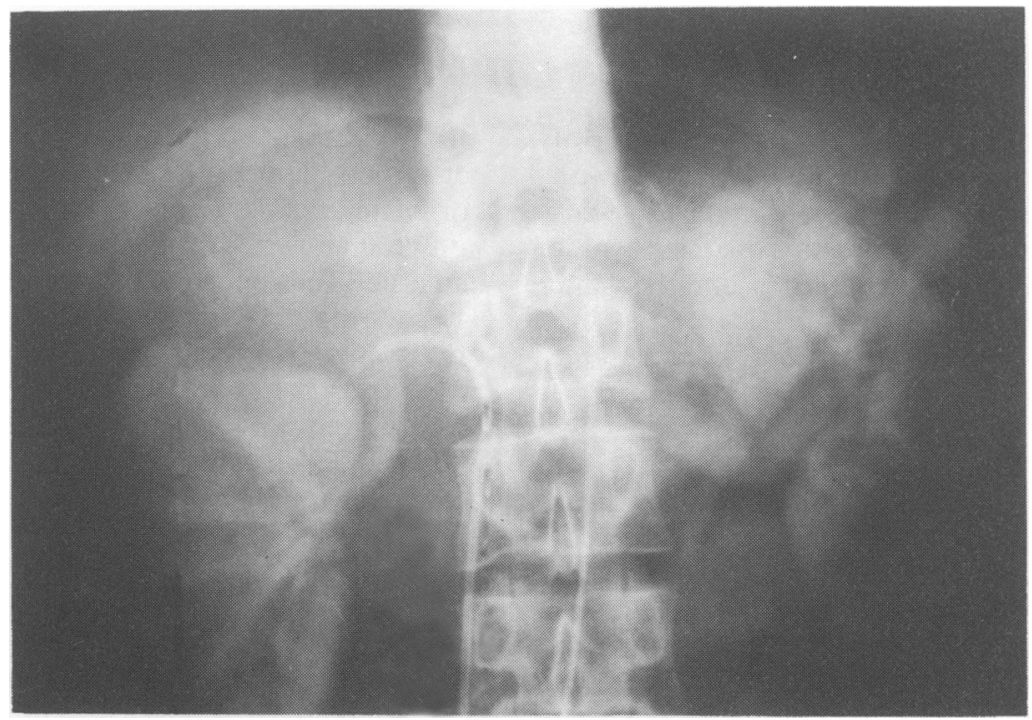

Figure 2 Renal angiogram showing a large mass above the right kidney.

generation computed tomographic (CT) scan at this time confirmed the presence of a right adrenal mass and failed to reveal any other masses.

The patient's hypertension was controlled using oral phenoxybenzamine and propranolol for 10 days prior to operation. At operation the right adrenal gland was found to be replaced by a yellow/green tumour $250 \mathrm{~g}$ in weight. The right renal artery was not compressed by tumour or by fibrous bands. Tumour histology was characteristic of phaeochromocytoma, vascular invasion was not demonstrated. Immunocytochemistry showed strong uptake of the protein $N$ gene product (PGP) 9.5, a neural marker. Electron- o microscopy revealed characteristic neurosecretory granules.

Post-operatively the patient made an uneventful $\stackrel{\mathbb{P}}{+}$ recovery but he remained hypertensive (BP 0 $180 / 120 \mathrm{mmHg}$ ). Repeat 24-hour urinary VMA levels, although less than pre-operatively were still elevated $\stackrel{\odot}{\circ}$ and plasma noradrenaline levels also remained high. 
A third generation CT scan demonstrated two further masses in the left adrenal gland. These were surgically removed. Their combined weight was $41 \mathrm{~g}$ and the histological appearance was identical to that of the first.

Post-operatively the blood pressure, urinary VMA and noradrenaline levels returned to normal. The patient required no further anti-hypertensive therapy, his medications being replacement cortisone acetate only.

One month after the second operation the right renal bruit was still audible. Repeat angiography demonstrated the right renal artery stenosis as before. Selective renin levels at this time had returned to normal although the level in the right renal vein $(3.02 \mathrm{pmol} / \mathrm{ml} / \mathrm{h})$ exceeded that in the left $(2.58 \mathrm{pmol} /$ $\mathrm{ml} / \mathrm{h}$ ). This was non-significant as the ratio of right to left did not exceed 1.5. Balloon angioplasty was performed, following which the stenosis could not be demonstrated and the renal artery bruit disappeared.

The patient remains well and normotensive 2 years following surgery, his only treatment being cortisone acetate replacement therapy.

\section{Discussion}

The first description of phaeochromocytoma with renal artery stenosis is attributed to Harrison. ${ }^{1}$ One year post successful removal of three left sided phaeochromocytomas ( 1 adrenal and 2 extra-adrenal) a 16 year old girl developed reno-vascular hypertension. The left renal artery was found at operation to be encased in dense scar tissue. The vessel had appeared normal at the time of her initial operation. Following excision no histological change was documented in the artery. Since then some $\mathbf{4 0}$ more cases have been reported. $^{2-35}$

The reason for the association between phaeochromocytoma and renal artery stenosis has not always been as clearcut as in the case described by Harrison. Naidich et al..$^{24}$ reported a patient who, 10 years following resection of two phaeochromocytomas, was found to have fibrous adhesions which appeared responsible for a smoothly contoured segmental stenosis in the mid-portion of the right renal artery. At operation the presence of compressive adhesions was confirmed. Soon afterwards the patient died. At post-mortem two residual right-sided extra-adrenal phaeochromocytomas were found one located immediately adjacent to the right renal artery producing minimal compression. No histological change was found within the renal artery. In this case both compression by tumour and catecholamine-induced spasm, together with the adhesions may have contributed to the renal artery stenosis.

Many cases of renal artery stenosis associated with phaeochromocytomas have been secondary to direct compression or stretching of the renal artery by tumour. ${ }^{15}$ Of 27 cases reviewed by Alvestrand et al., 16 were considered to be secondary to tumour compression. ${ }^{2}$ Valik et al. reported that $75 \%$ of tumours causing renal artery compression arise from the lumbar sympathetic chain on the side of the stenosis in the region of the renal hilum. ${ }^{37}$ However, the fact that the phaeochromocytoma may also be found at a distance from the stenosed renal artery points to other possible explanations. ${ }^{7,10,21,44}$

Six case reports indicate that the renal artery stenosis in association with phaeochromocytoma may be transient or reversible. In one case a 13 year old female died hours after renal angiography which demonstrated a right adrenal phaeochromocytoma with right and left renal artery stenosis and stenosis of the coeliac artery. At post-mortem the phaeochromocytoma was found but there was no evidence of stenosis in any of the aforementioned vessels. ${ }^{8}$ It has been suggested that the transient stenosis is due to catecholamine-induced spasm. Indeed, it has been demonstrated that such spasm can be induced by direct injection of adrenaline into the general circulation of dogs. ${ }^{38}$

In the majority of reported cases the renal artery stenosis has occurred on the same side as the tumour and in close proximity to it, thus, in the case of non-compressing tumours, the stenosis may be attributable to local hormone seepage rather than to elevated circulating hormone levels. Long term exposure of these vessels to the effects of high catecholamine concentrations may result in irreversible organic lesions. A variety of histological changes have been noted in such vessels including intimal fibrosis ${ }^{15}$ and fibro-muscular hyperplasia. ${ }^{32}$ In one case an atheromatous plaque causing renal artery stenosis was found in association with a phaeochromocytoma. ${ }^{25}$ Two cases have been described of phaeochromocytoma and renal artery stenosis occurring in Von Recklinghausen's neurofibromatosis. ${ }^{15,19}$ In one case the renal artery stenosis occurred many years after successful removal of a phaeochromocytoma, while in the other case they occurred simultaneously. As both fibromuscular dysplasia, causing renal artery stenosis, and phaeochromocytoma occur with increased frequency in Von Recklinghausen's disease, it is not surprising that they might occur by chance in the same patient. This occurrence was predicted by Thomas et al. but at the time of publication they could find no such report. ${ }^{31}$

The angiographic findings of renal artery stenosis in association with phaeochromocytoma are variable. ${ }^{24}$ Often the stricture escapes detection since the tumour compresses the artery from behind and flattens the vessel making it appear normal sized. Compressing tumours tend to cause smooth stenoses of the distal 
half of the renal artery with a variable degree of post-stenotic dilatation.

Stenoses adjacent to non-compressing tumours have variable reported angiographic appearances. A smooth segmental stenosis of the mid-portion of the renal artery with abrupt transition from normal to narrowed lumen was present in three cases. ${ }^{10,13,34}$ In one case there was irregular narrowing of the distal renal artery with extension into the branch vessels. ${ }^{41}$ Multiple tubular stenoses of various arteries including the renal artery were noted in one case ${ }^{8}$ Angiographic changes seen when fibromuscular dysplasia is associated with phaeochromocytoma have been described in 2 cases, one showed the typical beaded appearance of the renal artery, ${ }^{32}$ in the other there was smooth stenosis of the mid-portion of the renal artery with post-stenotic dilatation. ${ }^{18}$

The presence of an undiagnosed phaeochromocytoma in a patient undergoing renal angiography can prove fatal $^{8}$ and should be suspected if the patient develops severe hypertension or cardiac arrythmias during the procedure. We feel that in cases of suspected renovascular hypertension, the possibility of a coexisting phaeochromocytoma should be carefully considered before proceeding to angiography.

Plasma renin levels and renal vein renin ratios are undoubtedly of great value in the diagnosis of renovascular hypertension. Can the same criteria be applied to cases of renal artery stenosis complicated by the co-existence of one or more catecholamine producing tumours? Hiner found increased plasma renin activity in more than $70 \%$ of patients with phaeochromocytomas in whom it had been measured.$^{39}$ Elevated plasma renin levels in these patients may be due to associated renal artery disease or to vascular compression by tumour. Increased levels may also result from changes in intra-renal haemodynamics related to the effect of volume depletion or to high concentration of circulating catecholamines. In a comprehensive review

\section{References}

1. Harrison, J.H., Gardner, F.H. \& Dammin, G.J. A note on pheochromocytoma and renal hypertension. $J$ Urol 1958, 79: 173-178.

2. Alvestrand, A., Bergstrom, J. \& Wehle, B. Pheochromocytoma and renovascular hypertension. Acta Med Scand 1977, 202: $231-236$.

3. Bethea, M.C., Baltz, H.J., Rogers, R.E. \& Weichert, R.F. Pheochromocytoma and renal artery stenosis: a review of the literature and case report. South Med J 1973, 66: 497-500.

4. Castleman, B., Scully, R.E. \& McNeely, B.U. Case records of the Massachussetts General Hospital: case 19-1973. Presentation of case. N Engl J Med 1973, 288: $1010-1018$. of 37 cases of co-existing phaeochromocytoma and renal artery stenosis by Hill et al. ${ }^{9} 14$ patients had peripheral renin estimations all of which were found to be elevated. Six patients had renal vein renin ratios measured and all showed significant elevation (ratio $>1.5$ ). In our case renin levels were grossly elevated prior to operation at all sites of measurement. The renal vein renin ratio however did not exceed the level consistent with significant renal artery stenosis. Peripheral renin levels returned to normal after successful tumour removal despite the persistence of the renal bruit and angiographically proven stenosis.

These results suggest that renin levels were elevated in this case because of circulating catecholamine excess prior to surgical removal of the phaeochromocytomas. Renal vein renin estimations in this case indicate that the renal artery stenosis did not significantly contribute to the hypertension. Thus peripheral plasma renin levels may be elevated in such cases of dual pathology without clinically significant renal artery stenosis. However, renal vein renin sampling continues to be helpful in deciding, in each individual, to what extent the renal artery stenosis contributes to the hypertension and therefore, the management of the patient.

There seems, therefore, to be no single explanation why renal artery stenosis is associated with phaeochromocytoma. Compression by tumour or fibrous adhesions together with reversible or irreversible stenosis of the renal artery, caused by catecholamine excess, account for the majority of cases though the pathogenesis of the renal artery stenosis is by no means clearcut in every case. Likewise, angiographic appearances vary in accordance with the cause of the renal artery stenosis. The detailed investigations in our patient suggest that renin levels were elevated because of circulating catecholamine excess prior to surgical removal of the phaeochromocytomas and point to circulating catecholamine excess as the possible explanation of the coincidence for the two conditions.

5. D’Affito, V. \& Zannini, G. Ipertensione arteriosa con ipotension-eortostatica associata a feocromocitoma $\mathrm{e}$ ipoplasia dell, arteria renale destra con ispessimento intimale e rene piccola. La Reforma Medica 1965, 70: 813-821.

6. Del Gaudio, A.. Pheochromocytoma and renal artery stenosis. Int Surg 1985, 70: 153-158.

7. Ecoiffer, J., Leval-Jeanlet, M. \& Koressions, J.C. Contributions de l'arteriographie au diagnostic des pheochromocytomes. Ann Radiol (Paris) 1966, 9: 703-709.

8. Ecoiffer, J., Fournier, A., Leduc, G. \& Plainfosse, M.C. Quelle signification peut-on accorder a la decouverte arteriographique de stenoses au cours des pheochromocytomes. Presse Med 1970, 78: 2325-2328. 
9. Hill, F.S., Jander, H.P., Murad, T. \& Diethelm, A.G. The coexistence of renal artery stenosis and pheochromocytoma. Ann Surg 1983, 197: 484-490.

10. Garrett, H.E., Scott, R. Jr, Howell, J.F. \& De Bakey, M.E. Pheochromocytoma and renovascular hypertension. Acta Med Scand 1977, 90: 97-100.

11. Goergakakis, A.K. Chromaffin cell tumours, a review of ten cases. Br J Surg 1971, 58: 895-900.

12. Herberer, G., Engelking, R. \& Eigler, F.W. Diagnostische und therapeutische besonderheiten bei einigen hochdruckkranken mit nierenarterienstenosen. Dtsch Med Wochenschr 1967, 92: 581-592.

13. Hudson, P. Clinicopathologic conference. New Physician 1969, 18: $308-316$.

14. Ishibasha, M., Takeuchi, A., Yokoyama, S. et al. Pheochromocytoma with renal artery stenosis and high plasma renin activity. Jpn Heart $J$ 1975, 16: $741-748$.

15. Kauffman, J.J., Marks, L.S. \& Smith, R.B. Stenosis of the renal artery and coexistent lesions. Surg Gynecol Obstet 1974, 139: 59-64.

16. Kerzner, M.S., Reeves, J.A., Denyse, D. \& Claunch, B.C. Pheochromocytoma with renal artery compression in an identical twin. Arch Intern Med 1968, 121: 91-94.

17. Kishikawa, H., Tsuji, H., Takagi, I. et al. Hemorrhagic necrosis of pheochromocytoma associated with reversible renal artery stenosis. Jpn J Surg 1986, 16: 46-51.

18. Kwan, V.W., Hawkins, L.W. \& Lerwick, E.R. Pheochromocytoma and renal artery stenosis. South Med J 1970, 63: $114-115$.

19. Kremen, A.F., Hill, E. \& Kremen, A.J. Pheochromocytoma, renal artery stenosis and lymphocytic lymphoma associated with Von Recklinghausen's neurofibromatosis, case report and literature review. Minn Med 1985, 68: 99-101.

20. Maebash, M., Miura, Y.\& Yoshinaga, K. Plasma renin activity in pheochromocytoma. Jpn Circ J 1968, 32: 1427-1432.

21. Mannhart, M., Ludin, H., Veyrat, R. \& Ziegler, W.H. Secondary hyperaldosteronism caused by cervical pheochromocytoma, cure by ablation of the tumour. Helv Med Acta 1969, 35: 479-483.

22. Marchal, C. \& Saplier, P. Hypertension arterielle, stenose d'arterie renale et pheochromocytome. Med Infant 1967, 74: 341-343.

23. Milliez, P., Bourel, M., Fritel, D., Tcherdahoff, P.H. \& Samarcq, P. Pheochromocytome du pedicle vasculaire renal. Bull Soc Med Hosp Paris 1963, 114: 1027.

24. Naidich, T.P., Sprayreger, S., Goldman, A.G. \& Siegelman, S.S. Renal artery alterations associated with pheochromocytoma. Angiology 1972, 23: 488-499.

25. McBride, J.W. \& Fitz, A. Renal artery stenosis, pheochromocytoma and erythrocytosis. Am J Med 1971, 51: 403-411.

26. Raghavaiah, N.V. \& Singh, S.M. Extra-adrenal pheochromocytoma producing renal artery stenosis. $J$ Urol 1976, 116: 243-245.
27. Rosenheim, M.L., Ross, E.J., Wrong, D.M. et al Unilateral renal ischaemia due to compression of a renal artery by a pheochromocytoma. Am J Med 1963, 34: $735-740$.

28. Sato, T., Sahamoto, S., Maebashi, M. et al. Hypertension due to a combination of pheochromocytoma and unilateral renal ischaemia by tumour compression. Jpn Heart J 1967, 8: 202-208.

29. Seringe, P., Plainfosse, B., Debrun, G. et al. Phenochromocytoma bilateral et stenose unilaterale de l'artere renale chez en enfant. Operation. Guerison. Etude en microscope electronique. Ann Pediatr (Paris) 1968, 44: 714-727.

30. Straube, K.R. \& Hodges, C.V. Pheochromocytoma causing renal hypertension. Am J Roentgenol 1966, 98: $222-224$.

31. Thomas, C., Kolhatkar, R.K., Sharma, N.L. \& Deodhare, S.G. Phaeochromocytoma with unilateral renal stenosis. Postgrad Med J 1976, 52: $793-795$.

32. Tinguely, H., Bopp, P. \& Wettstein, P. Association pheochromocytome-hyperplasie fibro-musculaire: Coincidence ou entite nosologique. Radiologia Clinica Biol 1966, 35: $311-315$.

33. Tisherman, S.E., Gregg, F.J. \& Danowski, T.S. Familial pheochromocytoma. JAMA 1962, 18: 150-154.

34. Van Way, C.W., Michelicus, A.M., Alper, B.J. et al. Renal vein renin studies in a patient with renal hilar pheochromocytoma and renal artery stenosis. Ann Surg 1970, 172: $212-217$.

35. Weidmann, P., Siegenthaler, W., Ziegler, W.H. et al. Hypertension associated with tumours adjacent to renal arteries. Am J Med 1969, 47: 528-533.

36. Weiss, M., Muller, H., Kropelin, T. \& Kluthe, E. Nierenarterienstenose and phaeochromozytom. Verh Dtsch Ges Inn Med 1973, 79: 812-814.

37. Velik, W.F., Bookstein, J.J. \& Talner, L.B. Pheochromocytoma with reversible renal artery stenosis. Am J Roentgenol 1978, 131: 1069-1071.

38. Abrams, H.L., Bdijsen, E. \& Borgstrom, K. Effects of epinephrine on the renal circulation. Angiographic observations. Radiology 1962, 79: 911-922.

39. Hiner, L.B., Gruskin, A.B., Baluarte, H.J. et al. Plasma renin activity and intra renal blood flow distribution in a child with pheochromocytoma. J Pediatr 1976, 89: 950-952.

40. Weber, A.L. Ganower, M.L. \& Griscom, N.T. Radiologic and clinical evaluation of pheochromocytoma in children: Report of 6 cases. Radiology 1967, 88: 117.

41. Boijsen, E., Williams, C.M. \& Judkins, M.P. Angiography of pheochromocytoma. Am J Roentgenol 1966, 98: 225. 